\title{
O Pós-graduação e a formação de professores de educação física no Brasil
}

http://dx.doi.org/10.11606/1807-55092017000nesp071

\section{Introdução}

Celebramos com regozijo os 40 anos do curso de pós-graduação estrito senso em Educação Física e Esporte da Universidade de São Paulo (PPGEEFE-USP). Foi o pioneiro, o carro chefe da pós-graduação. Portanto, celebramos ao lado da Escola de Educação Física e Esporte da USP quarenta anos de pós-graduação em Educação Física no Brasil. Sou parte dessa geração, convivi e sou amigo fraterno de colegas que fizeram parte da primeira turma de alunos do mestrado. Alguns deles tornaram-se professores do PPG e por sua trajetória de tantos méritos são reconhecidos nacional e internacionalmente.

Com Alberto Carlos Amadio e Go Tani, ao lado de António Marques e Jorge Bento da Universidade do Porto e António Prista da Universidade Pedagógica de Maputo realizamos o primeiro doutorado tripartite, com estudantes do Brasil, Portugal e Moçambique. Os estudantes do programa estiveram na UFRGS em Porto Alegre, na USP em São Paulo, na FADE no Porto e na FEFD em Maputo. Ainda hoje esses estudantes mantém relações pessoais e institucionais muito produtivas. O sucesso dessa empreitada fez-nos sonhar com a esperança de um novo projeto entre os países de língua portuguesa, mas infelizmente nossas aspiraçóes não se concretizaram e o programa náo foi além dessa primeira experiência. A burocracia universitária, a falta de apoio dos órgãos de fomento, as dificuldades
Adroaldo Cezar Araújo GAYA****

operacionais e, porque não dizer, a carência de um sentimento mais profundo de amor a lusofonia entre muitos de nossos pares, náo permitiram manter o projeto além da primeira edição.

Parabéns aos professores, estudantes e técnicos administrativos do PPGEEFE-USP. Aos pioneiros que nos idos de 1976 tiveram a clarividência, a coragem e a competência para colocar o barco nas águas turvas de um trajeto desconhecido. Propor tamanha empreitada é um feito ao qual manifesto meu profundo reconhecimento. Aos professores mais experientes que remaram com força, velocidade, resistência e que enfrentaram Adamastor meu respeito e, aos mais jovens, a quem cabe a responsabilidade de levar o barco a horizontes infinitos minha admiração.

São 40 anos de pós-graduação em educação física no Brasil. É hora de um balanço. É hora de olharmos para o caminho que trilhamos e avaliar o estado da arte que construímos. Faz-se mister refletir sobre nossa obra coletiva. Este é o objetivo deste ensaio. Todavia, são muitas as perspectivas sobre as quais podemos admirar nossa obra, não obstante vou delimitar um espaço entre fronteiras bem demarcadas. Vou discorrer sobre como interpreto a influência dos programas de pós-graduação em educação física e esporte sobre a formação do professor de educação física e esportes no Brasil e propor alternativas.
${ }^{*}$ Escola Superior de Educação Física, Universidade Federa do Rio Grande do Sul, Porto Alegre, RS, Brasil.

${ }^{* *}$ Conselho Nacional de Desenvolvimento Científico e Tecnológico, Brasília, DF, Brasil. 


\section{Proponho uma metáfora}

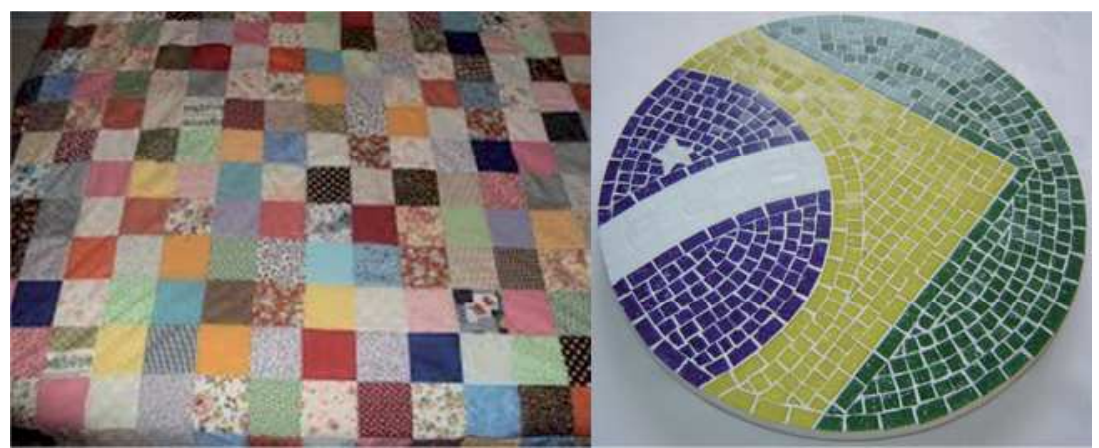

À esquerda temos uma colcha de retalhos: colorida, alegre, muito bonita e elegante e que cumpre sua funçáo de colcha se colocada sobra a cama. À direita temos um mosaico: também colorido, bonito e elegante. Todavia, nota-se uma relevante diferença se compararmos a colcha de retalhos e o mosaico. No mosaico as peças são intencionalmente organizadas para cumprir uma outra finalidade: compor a bandeira do Brasil. A figura que as peças formam tem um simbolismo, um significado. Portanto, diferentemente da colcha de retalhos, as peças são recortadas e coladas a partir de um plano previamente estabelecido, dá-se a partir de um significado, de um intensão: constituir a bandeira do Brasil.

$\mathrm{Na}$ metáfora que lhes proponho as peças do mosaico ou os retalhos da colcha representam as disciplinas científicas que compóe os currículos dos cursos de formação de professores de educação física. A colcha de retalhos ou o mosaico representam os currículos.

É evidente que se espera de um currículo de formação profissional que ele tenha um claro objetivo, enfim, que ele tenha a perspectiva de formar um bom professor. Portanto, um currículo deve assemelhar-se a um mosaico.

O que pretendo demonstrar neste ensaio é que nossos currículos dos cursos de formação de professores de educaçáo física, muito influenciados pela cultura dos programas de pós-graduação, são colchas de retalhos, estão distantes de um mosaico.

Para sustentar tais argumentos proponho as seguintes premissas:

1. O paradigma científico hegemônico nos cursos de formação de professores de educação física e esporte são radicalmente influenciados pela ideologia predominante dos cursos de pós-graduação. Neste contexto epistemológico reina soberano o paradigma da especialização disciplinar. Nele, cada vez mais, as diversas disciplinas isolam-se no interior de suas fronteiras metodológicas e epistemológicas e, cada vez menos, se comunicam entre si.

2. Neste contexto, os currículos dos cursos de formação de professores de educaçáo física incharam de tantas fisiologias, bioquímicas, biomecânicas, psicologias, antropologias, estatísticas e, por outro lado, esvaziaram-se de seu conteúdo pedagógico, filosófico e político.

3. Ainda, neste contexto os currículos assumiram um perfil epistemológico radicalmente multidisciplinar na medida em que habitam num mesmo espaço de formação diversas disciplinas científicas que, no entanto, são peças de um quebracabeças sem solução. Refez-se o mito da Torre de Babel, cada especialidade fala numa linguagem própria e hermética e já ninguém se entende. É uma colcha de retalhos.

Se nossas premissas são pertinentes podemos sugerir a seguinte tese:

O modelo de ciência multidisciplinar hegemônico nos cursos de pós-graduação transferiu-se para os cursos de graduação e, deste modo, constituiuse num relevante obstáculo epistemológico para a concepção de teorias pedagógicas, políticas e filosóficas inerentes a formação de professores de educação física e esporte.

Dito de outra forma, a compreensão sobre o todo - a educaçáo física e o esporte - está cada vez mais fragmentada nas suas disciplinas especializadas. Implodimos os conhecimentos em múltiplos fragmentos (as disciplinas científicas) e corremos o risco de não mais reencontrarmos nossa matriz complexa e transdisciplinar. Assim, perde sentido, e representatividade na formação dos professores a reflexão epistemológica e o conhecimento pedagógico.

Como funciona este modelo de formação de nossos professores estruturado hegemonicamente sobre o paradigma do conhecimento científico multidisciplinar? 


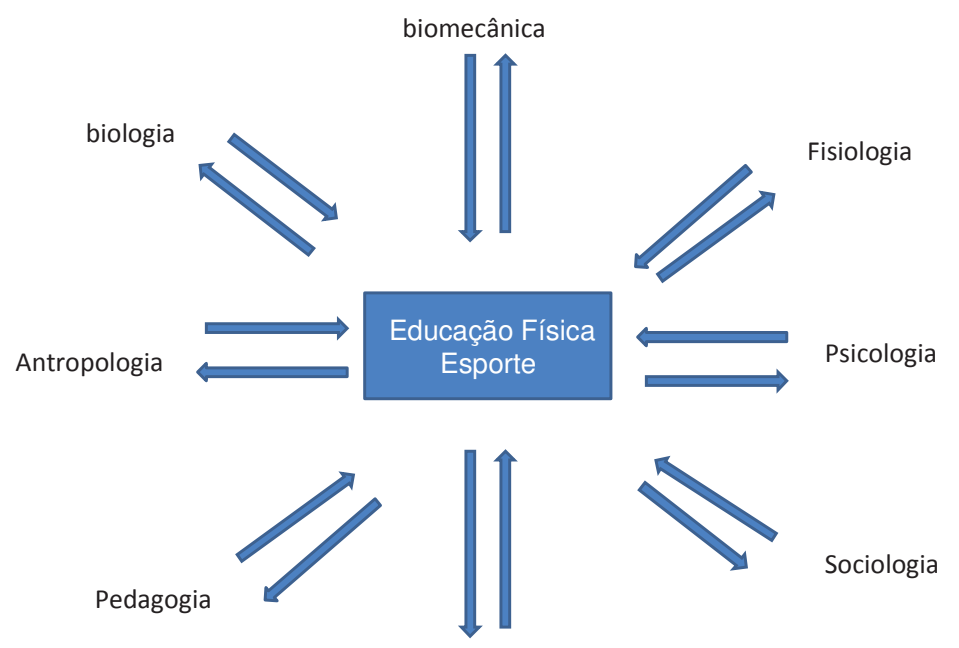

Filosofia

FIGURA 1 - Modelo multidisciplianar.

Neste paradigma multidisciplinar predominante em nossa contemporaneidade:

1. As diversas disciplinas isolam-se em suas perspectivas de análises. Em outras palavras, não há comunicação entre elas. São metodologias, linguagens, comunidades, periódicos e congressos distintos. Um arquipélago onde cada ilha se sente autossuficiente e não compartilha e talvez nem enxergue suas circunvizinhas.

Esquecem os adeptos deste modelo multidisciplinar que seus conhecimentos científicos disciplinares serão sempre incompletos, fragmentados, provisórios e probabilísticos. Desculpem a ironia e a provocação, mas o conhecimento científico tal como se manifesta em nosso modelo hegemônico, sofre de glaucoma. Ele reduz o campo da visão periférica. Tem dificuldade de enxergar além do que está posto à sua frente.

2. Os temas de pesquisa são gerados no ventre das disciplinas mães. Ou seja, as questôes de pesquisa respondem principalmente às necessidades da fisiologia, da biomecânica, da antropologia, etc., e não as necessidades oriundas das práticas de intervenção na educação física e esportes. $\mathrm{O}$ produto das pesquisas constitui conhecimentos que, normalmente, retornam às disciplinas mães. Portanto, a educaçáo física e o esporte são apenas o "lócus" onde biólogos, psicólogos, sociólogos e antropólogos refletem em seus espelhos suas curiosidades científicas. Os conhecimentos dos biólogos retornam à biologia, dos psicólogos a psicologia..., pouco destes conhecimentos respondem as questóes inerentes à pedagogia da educaçấo física e dos esportes. Há inclusive, por parte de alguns cientistas das áreas biológicas, uma forte rejeição aos conhecimentos pedagógicos e filosóficos.

Sendo assim:

3. Se minhas conjeturas estáo corretas, esse modelo multidisciplinar de produção do conhecimento não permite a configuração de teorias gerais que sustentam o arcabouço das práticas pedagógicas em educaçáo física e esporte. Só vemos partes, cada vez menores (é como se nosso glaucoma avançasse aceleradamente). Nesta perspectiva nossos cursos de formação preocupam-se principalmente em formar pesquisadores em fisiologia, biomecânica, psicologia, antropologia, sociologia, etc., e esquecem de formar professores de educação física e treinadores esportivos. Este fenômeno é evidente quando identificamos alunos que são capazes de publicar artigos científicos em revistas de alto impacto (evidentemente acompanhados de seu orientador e mais ou menos 12 coautores como agora é a moda em nossa comunidade científica) no entanto, tremem dos pés à cabeça ao enfrentar uma turma de alunos do $9^{0}$. ano do ensino fundamental para uma aula de educação física ou esportes.

Mas que alternativas podemos supor para superar este modelo de formação centrado no paradigma multidisciplinar? Que alternativas permitem uma configuração curricular dos cursos de formação em educação física e esporte que integre o conhecimento científico disciplinar numa ecologia de saberes? Como supor a integraçáo dos conhecimentos oriundos de tantas disciplinas especializadas num conhecimento complexo? Qual o caminho para 
recorrer ao conhecimento científico especializado da fisiologia, da biomecânica, da bioquímica, da psicologia, da sociologia, da antropologia para constituir pedagogias que deem subsídios às práticas de intervenção de professores de educação física e esporte?

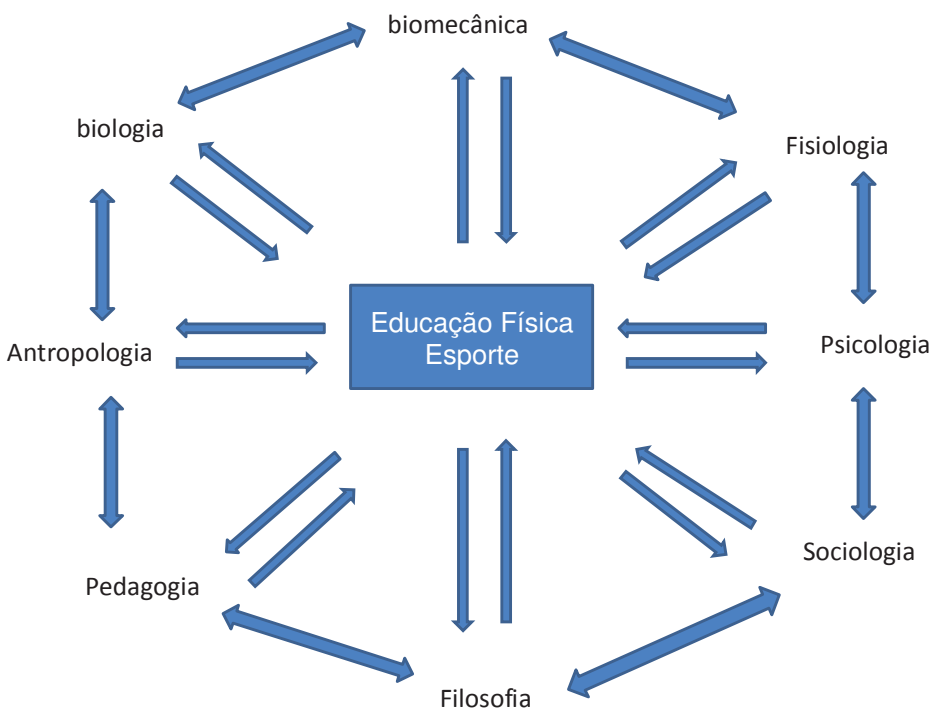

FIGURA 2 - Modelo transdisciplinar.

$\mathrm{Na}$ segunda figura pretendo sugerir o modelo transdisciplinar. Uma abordagem epistemológica que possibilita, pelo menos no âmbito do conhecimento científico, uma tentativa de exercitarmos o diálogo ou, como refere Hugo Lovisolo, a arte da mediação. Proponho a seguinte análise:

1. As setas que ligam o esporte às disciplinas científicas na segunda figura inverteram-se em relação à primeira figura. Isto significa uma mudança radical na perspectiva da produçáo e aplicaçáo do conhecimento científico. Explico: a primeira figura sugere que as questóes das pesquisas nascem da curiosidade de biólogos, biomecânicos, psicólogos, sociólogos e antropólogos. Os pesquisadores estão preocupados em produzir conhecimentos para a biologia, a psicologia, a biomecânica, a sociologia, a história, etc. Enfim, não estão preocupados com as demandas de conhecimentos oriundas das práticas pedagógicas em educação física e esporte. A educação física e o esporte são os meios. É o "lócus" onde se realiza a pesquisa. Por isso na primeira figura as setas retornam para a origem.

A segunda figura sugere que os problemas de pesquisa devem nascer das necessidades advindas da própria educação física e das práticas esportivas. Problemas esses que exigirão evidentemente conhecimentos especializados. Questiona-se a fisiologia, a biomecânica, a psicologia, a sociologia para que essas disciplinas especializada possam subsidiar os problemas que nasceram no âmbito das práticas pedagógicas (para que possamos fazer um mosaico).

As disciplinas especializadas nesta perspectiva devem propiciar conhecimentos que aplicados diretamente à educação física e aos esporte. Agora as setas retornam para educaçáo física e os esportes.

2. Todavia, esta mudança de sentido exige alteraçóes radicais na prática de produzir conhecimentos. Em primeiro lugar, é evidente que o pesquisador da educaçáo física e dos esportes não é um especialista em fisiologista, biomecânica, psicologia, sociologia, antropologia, etc. É um professor de educação física, um treinador, um preparador físico, um pedagogo que em algum momento de sua atividade se depara com problemas que exigem conhecimentos provenientes das distintas disciplinas científicas para constituir teorias que possam subsidiar sua prática profissional (a construção de um mosaico).

$\mathrm{O}$ pesquisador em educação física e esporte não é um cientista do tipo tradicional, desses que hoje formamos em nossos cursos de pósgraduação. Ele não é um especialista disciplinar. Seu conhecimento exige a arte da mediaçáo e, como tal, não pode limitar-se ao modelo disciplinar da ciência hegemônica. Como afirma Edgar Morin ${ }^{2}$ 
este pesquisador é um contrabandista de saberes. Ele precisa ultrapassar as fronteiras dos conhecimentos disciplinares e traficar informações, criar modelos híbridos. Como na metáfora de Michel Serres ${ }^{3}$, este pesquisador em educação física e esporte é um arlequim com trapos de várias cores a compor um traje alegre e adequado à sua nobre função de palhaço.

\section{Referências}

1. Gaya A. Educação física: ordem, caos e utopia. Belo Horizonte: Fundação Casa da Educação Física; 2014.

2. Morin E. Contrabandistas de saberes. In. Pessis-Pasternsak G. Do caos à inteligência artificial. 2a ed. São Paulo: UNESP; 1993.

3. Serres M. O terceiro instruído. Lisboa: Instituto Piaget; [data desconhecida].

ENDEREÇO

Adroaldo Cezar Araújo Gaya

Departamento de Educação

Escola Superior de Educação Física Universidade Federal do Rio Grande do Sul

R. Felizardo, 750

90690-200 - Porto Alegre - RS - BRASIL

e-mail: acgaya@esef.ufrgs.br 